\title{
Development of the workflow kine systems for support on KAIZEN
}

\author{
Yuki MIZUNO a,b, ${ }^{\text {, }}$, Toshihiko ITO ${ }^{\mathrm{c}}$, Toru YOSHIKAWA ${ }^{\mathrm{b}}$, Satoshi YOMOGIDA ${ }^{\mathrm{c}}$, Koji MORIO $^{\mathrm{d}}$, \\ Kazuhiro SAKAI ${ }^{\mathrm{b}}$ \\ ${ }^{a}$ Toyo Gakuen University Center for Liberal Arts, Tokyo, Japan \\ ${ }^{\mathrm{b}}$ Department of Research, The Institute for Science of Labour, Kawasaki, Japan \\ ${ }^{\mathrm{c}}$ DSS Co., Ltd., Sendai, Japan \\ ${ }^{\mathrm{d}}$ Institute for Medical Engineering Integration, Yokohama, Japan
}

\begin{abstract}
In this paper, we introduce the new workflow line system consisted of the location and image recording, which led to the acquisition of workflow information and the analysis display. From the results of workflow line investigation, we considered the anticipated effects and the problems on KAIZEN. Workflow line information included the location information and action contents information. These technologies suggest the viewpoints to help improvement, for example, exclusion of useless movement, the redesign of layout and the review of work procedure. Manufacturing factory, it was clear that there was much movement from the standard operation place and accumulation residence time. The following was shown as a result of this investigation, to be concrete, the efficient layout was suggested by this system. In the case of the hospital, similarly, it is pointed out that the workflow has the problem of layout and setup operations based on the effective movement pattern of the experts. This system could adapt to routine work, including as well as non-routine work. By the development of this system which can fit and adapt to industrial diversification, more effective "visual management" (visualization of work) is expected in the future.
\end{abstract}

Keywords: Location system, Workflow line, Location information display system, KAIZEN, Visual Management

\section{Introduction}

In this study, we developed the new workflow line system consisted of the location and image processing, which led to the acquisition of workflow information and the analysis display. From the results of workflow line investigation, we considered the anticipated effects and the problems on KAIZEN. Workflow line information included the location information by the location detector combined receiver (ankle sensor) and communicators (milestone) and action contents information by the image processing with small-size portable video camera. The workflow line information indicates visually-presented workflow and sojourn time. These technologies suggest the viewpoints to help improvement, for example, exclusion of useless movement, the redesign of layout and the review of work procedure.

\section{Method}

\subsection{Hard-Wear}

The configurations of hard-wear are receiver; $70 \mathrm{~mm}$ high, $50 \mathrm{~mm}$ width, $23 \mathrm{~mm}$ thick and 110 grams, communicators; $100 \mathrm{~mm}$ high, $74 \mathrm{~mm}$ width, and $24 \mathrm{~mm}$ thick, and small-size portable video camera; $73 \mathrm{~mm}$ high, $20 \mathrm{~mm}$ width, and $14 \mathrm{~mm}$ thick.

\subsection{Soft-Wear}

By using developed soft wear, the information obtained from analysis of survey data are 1) Workflow

\footnotetext{
*Corresponding author. E-mail: XLH02731@nifty.ne.jp
} 
figure mapped locus of moving, 2) Stay time of the milestone setting place, 3) Count number passed in the milestone setting place, 4) Walking speed, 5) Steps, and 6) Distance from the work base. In addition, this system can simulate the case that eliminate useless movement and the case that redesign of layout, and is provided with the function that display workflow line data.

Workflow line at the manufacturing factory and the medical facility were investigated using this system.

\section{Results}

According to the result in the manufacturing factory, it shows that movements to location away from standard operation area were much (Fig.1). Using the simulation function, it was examined the layout modification mainly on the point of extended movement. On-side workers carried out KAIZEN such as change of workflow line and layout change of parts and tools. As a result of workflow line after KAIZEN, wasting movement greatly-reduced and workflow focused the majority of standard operation area (Fig.2).

According to the result analyzed walk distance and course, movement of the nursing work (nursing duties and change of the work place), it showed the difference between movement course of skilled worker and non-skilled worker. The quality of health care work was able to improve by mapping the movement pattern of the skilled worker.
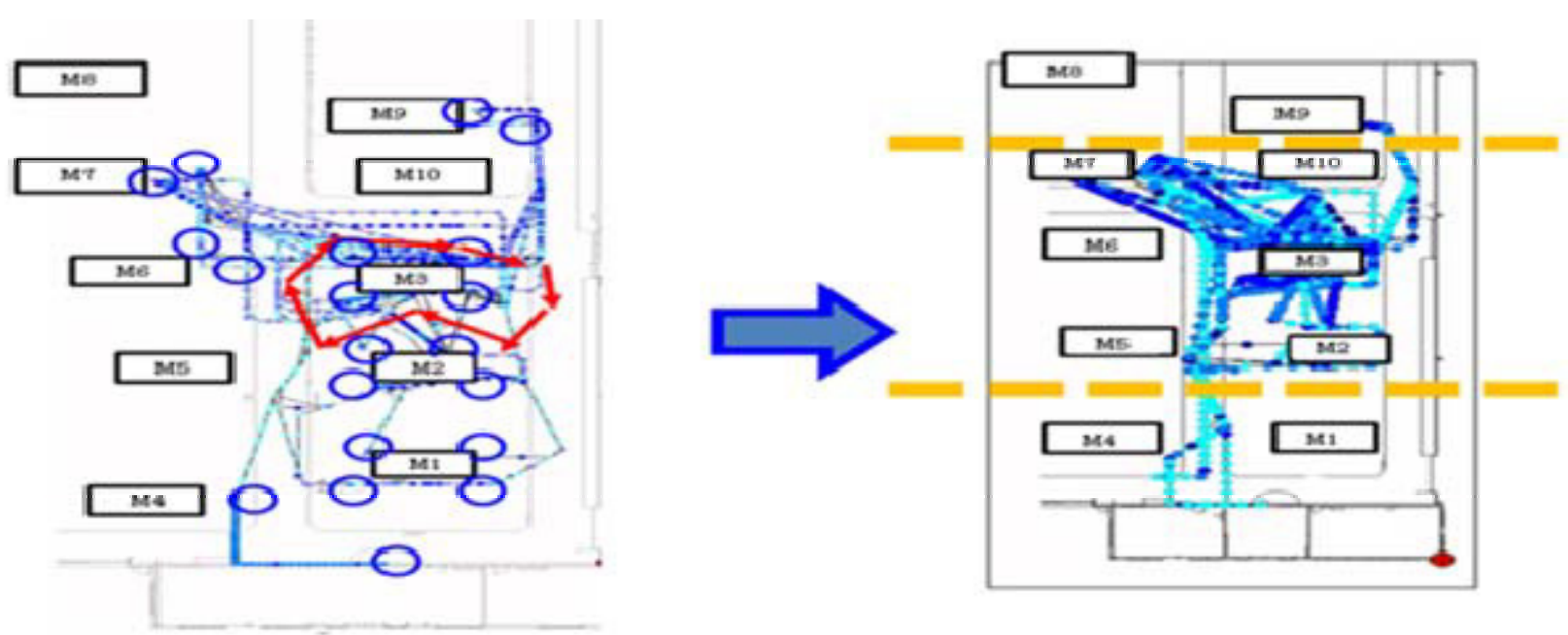

\section{Discussion}

In this study, the new workflow line system consisted of the location and image processing were evaluated the viewpoints to help improvement. In case of deference work such as the manufacturing factory and the medical facility, with this system, it extracted working problems and suggested the improvement easily. This system could adapt to routine work, including as well as non-routine work. By the development of this system which can fit and adapt to industrial diversification, more effective "visual management" is expected in the future

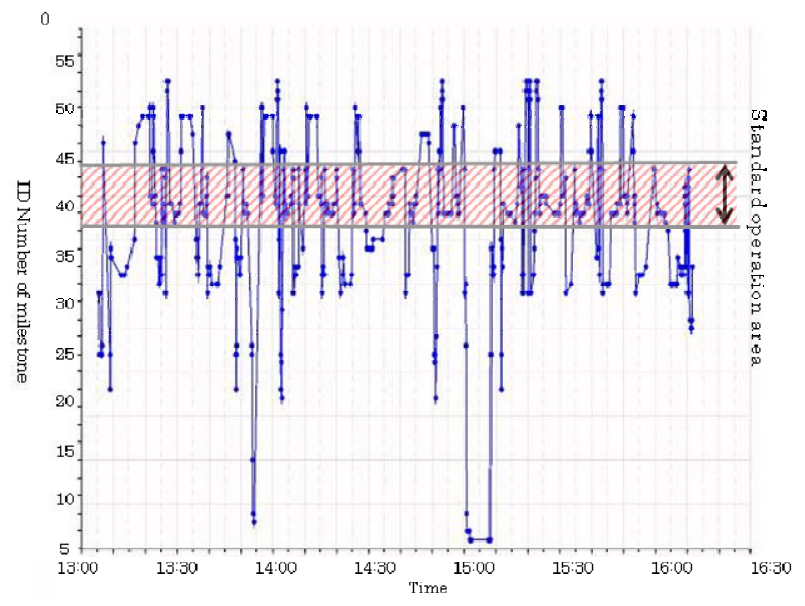

Fig.1 Moving route in workflow line surveying of factory

\section{Ground plan view (Number : Machine ID)}

Fig.2 Comparison of operation in workflow line after KAIZEN (left : before, right : after KAIZEN)

After KAIZEN, it is clear that workflow line was concentrated in the standard operation area (dotted line of the top and bottom). 